\title{
SHEAR MODULUS AND STRAIN OF LIQUEFIED GROUND AND THEIR APPLICATION TO EVALUATION OF THE RESPONSE OF FOUNDATION STRUCTURES
}

\author{
Shigeru MIWA 1 and Takaaki IKEDA ${ }^{2}$ \\ ${ }^{1}$ Member of JSCE, Research Institute of Technology, TOBISHIMA Corporation \\ (5472 Kimagase, Noda-shi, Chiba 270-0222, Japan) \\ E-mail: shugeru_miwa@tobishima.co.jp \\ ${ }^{2}$ Member of JSCE, Research Institute of Technology, TOBISHIMA Corporation \\ (5472 Kimagase, Noda-shi, Chiba 270-0222, Japan) \\ E-mail: takaaki_ikeda@tobishima.co.jp
}

\begin{abstract}
Since the seismic behavior of pile foundations in a liquefiable ground is primarily affected by the behavior of the ground, this paper discusses the usefulness of equivalent linear analysis considering the reduced shear modulus of liquefied soil for evaluating the dynamic behavior of liquefied ground. A multilumped mass model having liquefied soil springs set by reduced shear modulus is then applied to damaged buildings to verify its applicability. Shear strain levels and shear modulus in liquefied soil are also evaluated using strong motion records. In this light, a method of evaluating the reduced shear modulus of liquefied soil is proposed for dynamic analysis of liquefied ground by equivalent linear analysis
\end{abstract}

Key Words: liquefaction, soil-pile-interaction, equivalent linear method, shear modulus, shear strain

\section{INTRODUCTION}

The 1995 Hyogoken-Nambu earthquake caused severe liquefaction, which induced large ground displacement in horizontal directions over wide areas of reclaimed land. Liquefaction and the resulting flow caused serious damage to foundation structures, thereby tilting, moving, and severely damaging the superstructures. Investigations into pile damage (e.g., Reference 1)) revealed that damage to piles was mainly caused by the displacement of liquefied soil layers comprising reclaimed "masado" (decomposed granite soil) and that the large displacement occurred during the accumulation process of the excess pore water pressure or after liquefaction, i.e., later than the stage in which inertial forces by the main phase of strong motion acted ${ }^{1)}$. It is important to evaluate the behavior of a liquefiable ground for the seismic design of foundation structures to be built on such a ground. However, it is normally difficult to determine the parameters of soil for liquefaction analysis when soil investigation is not sufficient. It would be effective if there were a simplified method of evaluating the parameters of liquefied soil, such as shear strain or reduced shear modulus, for dynamic analysis of liquefied ground.

The The behavior of the ground during a strong motion, especially of a liquefied ground deposit, is nonstationary, with the shear modulus of soil dynamically changing in the time domain. Because the shear modulus of soil is set constant during an earthquake in equivalent linear analysis, although nonlinearity is considered in iteration, it is difficult to evaluate the behavior of the ground with strong nonlinearity during the strong ground motion in the time domain, especially for liquefied ground.

On the other hand, the behavior of deep foundations like piles during liquefaction is primarily affected by the displacement of the liquefied soil layer, rather than the inertial forces of 
the main phase of strong motion before liquefaction. It is therefore possible to enlarge the applicability of the equivalent linear method to the evaluation of the effect of liquefaction on piles, provided that the shear modulus during liquefaction is adequately estimated.

This paper discusses the development of multilumped mass soil-structure interaction analysis using the equivalent linear method for liquefied ground, and the evaluation of the shear modulus of liquefied soil.

Since the seismic behavior of pile foundations in a liquefiable ground is primarily affected by the behavior of liquefied soil, the first part of this paper discusses that equivalent linear analysis considering the reduced shear modulus of liquefied soil is useful for evaluating the dynamic behavior of liquefied ground. By using this method, the shear strain and equivalent shear modulus of liquefied ground are then evaluated based on the strong motion records observed during the Hyogoken-Nambu earthquake.

The liquefied soil springs of a multi-lumped mass model are then set based on the reduced shear modulus and the applicability of the model with equivalent linear analysis is verified by applying it to damaged buildings to examine the effect of liquefaction on pile foundations in comparison with the effective stress analysis.

It is necessary to obtain the dynamic deformation characteristics of a soil under large strain reaching several percent during liquefaction for applying the equivalent linear analysis to evaluation of the behavior of the liquefied ground. Since such data are scarcely available, the shear strain and shear modulus of liquefied soil during the HyogokenNambu earthquake and some other earthquakes are estimated using the observed records and effective stress analyses and are related to the liquefaction resistance ratio FL. Based on these results, a method of evaluating the reduction in the shear modulus of a liquefied soil using the liquefaction resistance ratio FL as an index is proposed for dynamic analysis of liquefied ground by the equivalent linear analysis method.

\section{SHEAR MODULUS AND SHEAR STRAIN OF THE LIQUEFIED LAYER DURING HYOGOKEN-NAMBU EARTHQUAKE}

\section{(1) Shear modulus and shear strain based on observed records at Kobe Port Island}

The 1995 Hyogoken-Nambu earthquake caused severe liquefaction over wide areas of reclaimed land comprising masado, with many sand boils being observed. In this section, the shear modulus reductions and shear strain of liquefied masado are sorted out referring to the literature.

The observation array in Port Island consists of accelerometers not only at G.L. $-84 \mathrm{~m}$ and the ground surface but also at the lower boundary of reclaimed masado or lower boundary of Holocene clay, with detailed soil investigation data being available. The behavior of the ground has therefore been investigated by various methods including backward analysis and direct analysis of the observed records to determine the shear modulus and shear strain, as well as various techniques for response analysis of the ground ${ }^{2-9}$. . The shear modulus reductions and shear strain estimated in past studies are shown in Table $1^{10)}$. The shear modulus decreased to a range between $1 / 20$ and $1 / 100$ of the initial value, causing shear strains of $1 \%$ to $4 \%$. Because these values are averages between the two depths where the accelerometers are set including non-liquefied layers, the actual shear modulus is considered to have been close to the lower limits of these estimations.

\section{(2) Evaluation based on records at East Kobe Bridge}

An investigation was conducted using the observed records at East Kobe Bridge ${ }^{11)}$ at Fukaehama Island, which was reclaimed earlier than Kobe Port Island, located at the east end of Kobe at a distance of about $25 \mathrm{~km}$ from the earthquake's epicenter. The observation site was reclaimed during the period between 1964 and 1970. The soil profile and analytical model of the East Kobe Bridge site are shown in Fig. 1. The $17 \mathrm{~m}$-thick surface layer consists of reclaimed decomposed granite soil with a relatively low SPT N-value of 3 to 11 . The soil layers can be regarded as being almost horizontally stratified from the results of soil investigations near the site. Seismographs were set at a level of G.L.$2.0 \mathrm{~m}$, which is regarded as the surface of the ground, and G.L.-34.0m, where the shear wave velocity is almost $300 \mathrm{~m} / \mathrm{s}$. The average shear strain determined by the relative displacement between the surface and underground obtained by doubly integrating the acceleration time histories is approximately $2 \%$ at the maximum. However, the shear strain of the masado layer is considered to be higher than this, as Holocene clay and Pleistocene alternation are contained between the two levels.

The 1-D effective stress method and 1-D equivalent linear method were therefore used for evaluating the shear modulus reductions and the shear strain of the masado layer. Effective stress analysis directly evaluates the changes in the effective stress by considering the rise of the excess 
Table 1 Reduction in the shear modulus and shear strain in liquefied decomposed granite soil based on observed records at Kobe Port Island site

\begin{tabular}{|c|c|c|c|c|c|}
\hline No. & $\begin{array}{c}\text { Ref. } \\
\text { No } \\
\end{array}$ & Author & $\begin{array}{l}\text { Reduction ratio of } \\
\text { shear modulus } \\
\end{array}$ & Shear strain & Method \\
\hline 1 & 2 & $\begin{array}{l}\text { Kazama \& } \\
\text { Yanagisawa }\end{array}$ & $0.04 \sim 0.06$ & $1 \sim 2$ & $\begin{array}{l}\text { Stress strain relationship of soil is } \\
\text { estimated from vertical array records }\end{array}$ \\
\hline 2 & 3 & Kokusho et al. & $0.04 \sim 0.06$ & $1 \sim 2.3$ & $\begin{array}{l}\text { Identified from vertical array records } \\
\text { by backward analysis }\end{array}$ \\
\hline 3 & 4 & $\begin{array}{l}\text { Yoshida \& } \\
\text { Kurita } \\
\end{array}$ & $0.01 \sim 0.02$ & $1 \sim 3$ & $\begin{array}{l}\text { Identified from vertical array records } \\
\text { by backward analysis }\end{array}$ \\
\hline 4 & 5 & Kawase et al. & 0.06 & 4 & $\begin{array}{l}\text { Shear wave velocity is estimated by the } \\
\text { propagation time of peak of coefficient } \\
\text { of cross-correlation }\end{array}$ \\
\hline 5 & 6 & Suzuki & 0.01 & - & $\begin{array}{l}\text { Identified from vertical array records } \\
\text { by backward analysis }\end{array}$ \\
\hline 6 & 7 & Morio et al. & 0.05 & - & $\begin{array}{l}\text { Propagation velocity from } \\
\text { spectrum and cross-correlation, stress } \\
\text { strain relation }\end{array}$ \\
\hline 7 & 8 & Miyata et al. & $0.01 \sim 0.015$ & - & $\begin{array}{l}\text { propagation velocity of peak of } \\
\text { observation records }\end{array}$ \\
\hline 8 & 9 & Mochizuki et al. & 0.05 & - & Cross-correlation analysis \\
\hline
\end{tabular}

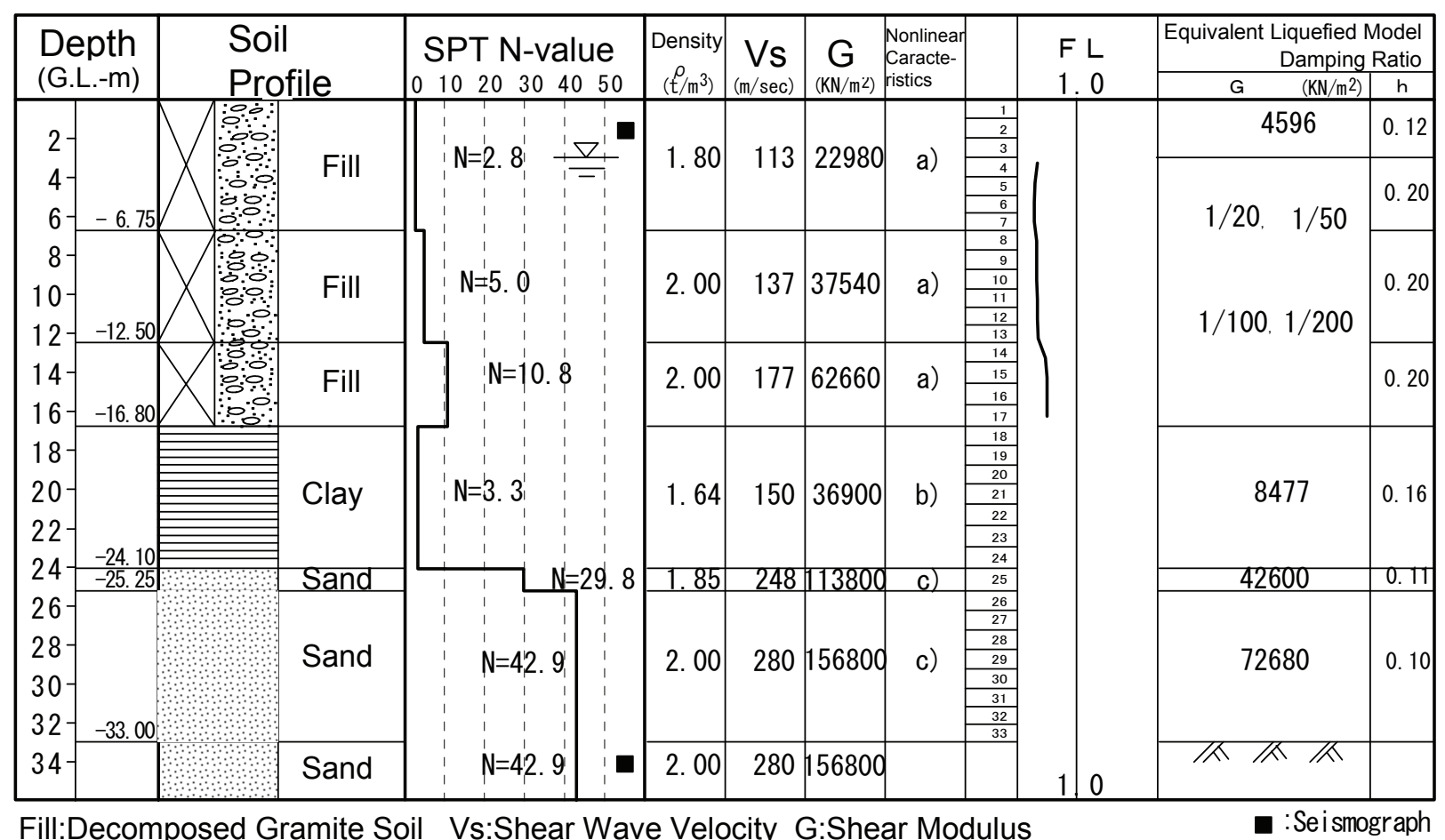

Fig. 1 Soil profile at East Kobe Bridge

pore water pressure. The codes of analysis employed for the effective stress method and the equivalent linear method were FLIP $^{12}$, which consists of the multi spring element model proposed by Towhata and Ishihara ${ }^{13)}$ and excess pore water pressure model proposed by Iai et al. ${ }^{12)}$, and SHAKE ${ }^{14)}$, respectively. Equivalent linear analysis evaluates the nonlinearity of the ground equivalently as a linear material. It is generally difficult for this method to examine the behavior of liquefied ground with a very large shear strain, though this method reportedly explains well the amplification of strong motion at a site where the excess pore pressure rose to $75 \%$ of the confining pressure ${ }^{15)}$. In this study, an attempt is made to accurately and simply evaluate the behavior of liquefied soft ground by estimating 


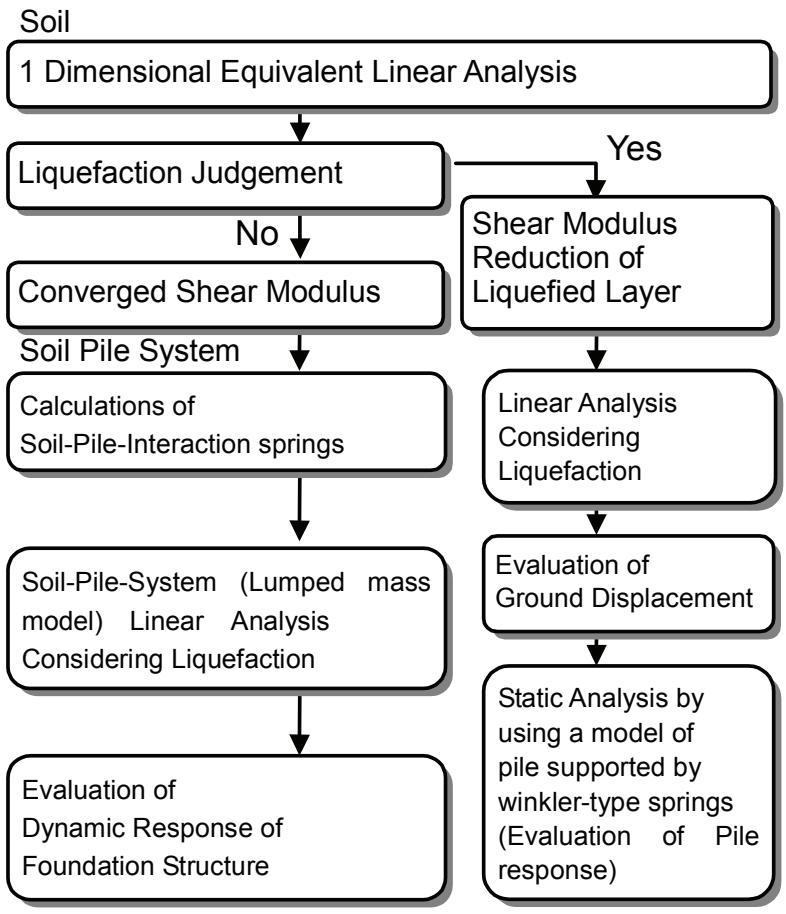

Fig. 2 Procedure of equivalent linear analysis considering liquefaction

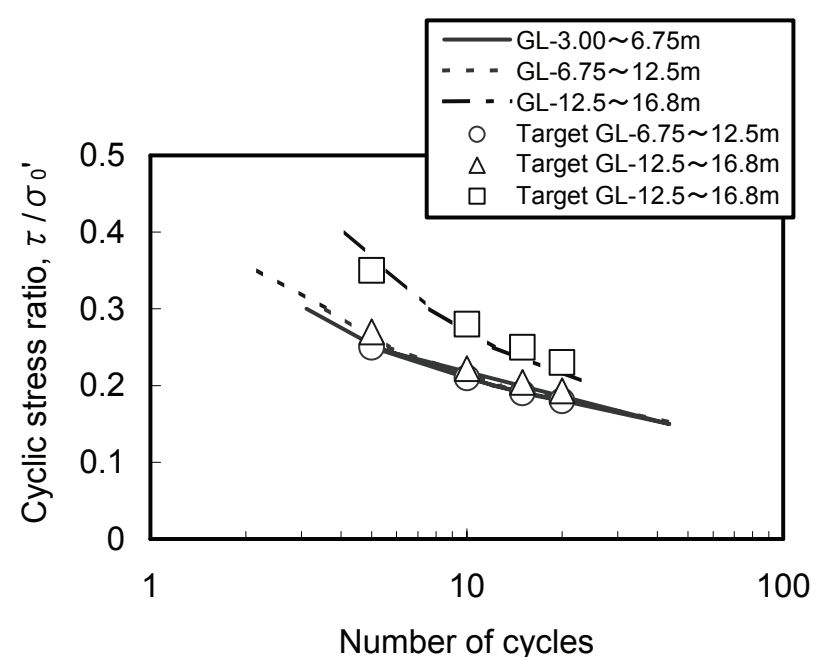

Fig. 3 Liquefaction resistance of reclaimed fill (Masado)

the reductions in the shear modulus of a liquefied layer.

The procedure begins with a normal equivalent linear analysis. A liquefaction potential assessment for liquefiable layers is then made by comparing the liquefaction strength with the shear stress estimated by the equivalent linear analysis. A reduced shear modulus considering liquefaction is given to the layer assessed as liquefiable, and a converged value
Table 2 Liquefaction parameters for reclaimed fill (Masado)

\begin{tabular}{ccccccccc}
\hline \hline & Rle20 & $\phi f$ & $\phi p$ & \multicolumn{5}{c}{ Parameter of dilatancy } \\
\cline { 5 - 9 } & & deg & deg & $\mathrm{S}_{1}$ & $\mathrm{~W}_{1}$ & $\mathrm{P}_{1}$ & $\mathrm{P}_{2}$ & $\mathrm{C}_{1}$ \\
\hline $\begin{array}{c}\text { GL-3.00 } \\
\sim-6.75 \mathrm{~m}\end{array}$ & 0.180 & 37.9 & 28 & 0.005 & 5.074 & 0.5 & 1.056 & 1.6 \\
\hline $\begin{array}{c}\text { GL-6.75 } \\
\sim-12.5 \mathrm{~m}\end{array}$ & 0.195 & 38.0 & 28 & 0.005 & 5.266 & 0.5 & 1.049 & 1.6 \\
\hline $\begin{array}{c}\text { GL-12.5 } \\
\sim-16.8 \mathrm{~m}\end{array}$ & 0.230 & 38.9 & 28 & 0.005 & 7.824 & 0.5 & 0.980 & 1.6 \\
\hline \hline
\end{tabular}

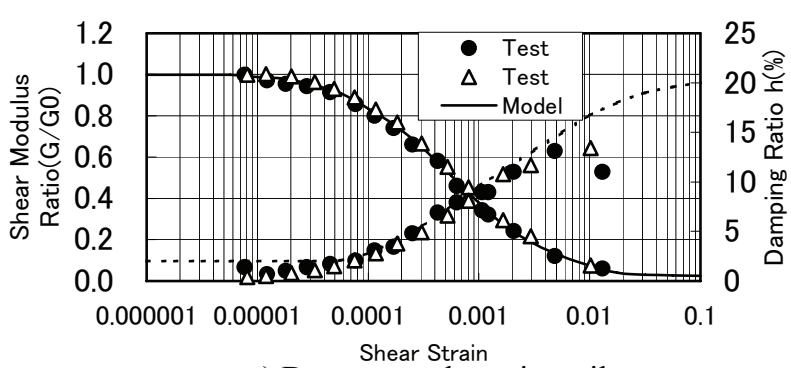

a) Decomposed granite soil

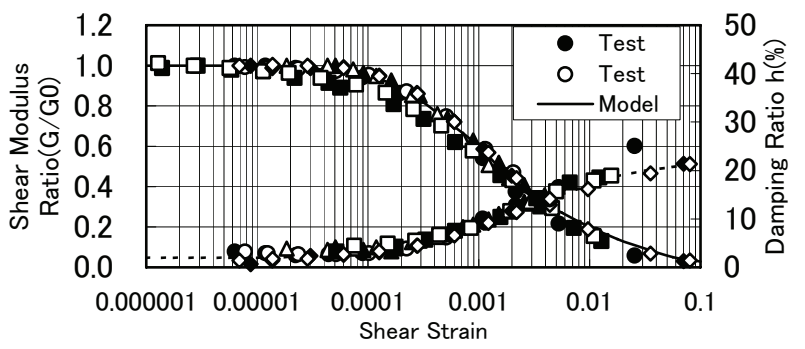

b) Alluvial clay

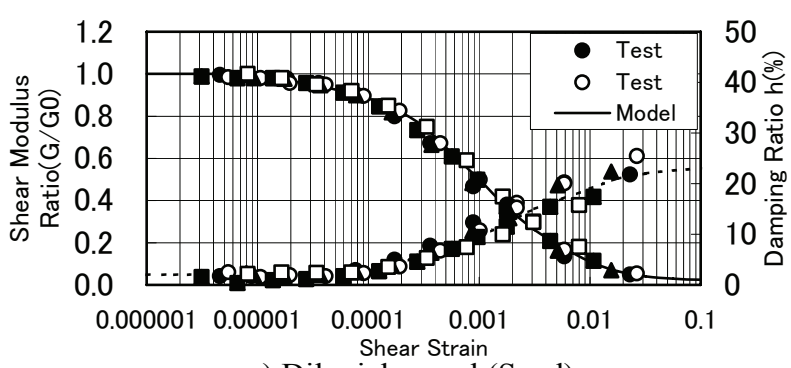

c) Diluvial gravel (Sand)

Fig. 4 Relation of shear modulus and damping ratio versus shear strain

obtained from the analysis is given to the other layers. A linear analysis is then carried out to evaluate the amplification of the ground containing a liquefied layer. In this paper, this two-step analysis is referred to as "equivalent linear analysis considering liquefaction" "16). This method has been proven capable of evaluating the behavior of liquefied ground in several other sites ${ }^{16), 17)}$. The procedure of equivalent linear analysis considering 

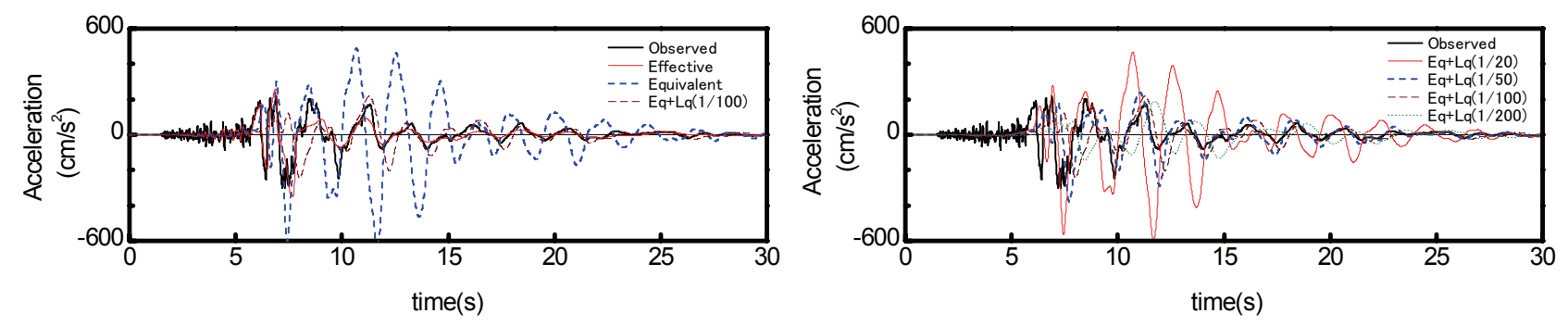

Effective :Effective Stress Method

Equivalent:Equivalent Linear Method

$\mathrm{Eq}+\mathrm{Lq}$ :Equivalent Linear Method considering Liquefaction (Shear Modulus:1/20, 1/50,1/100, 1/200)

Fig.5 Comparison of acceleration time histories at the surface (East Kobe Bridge)

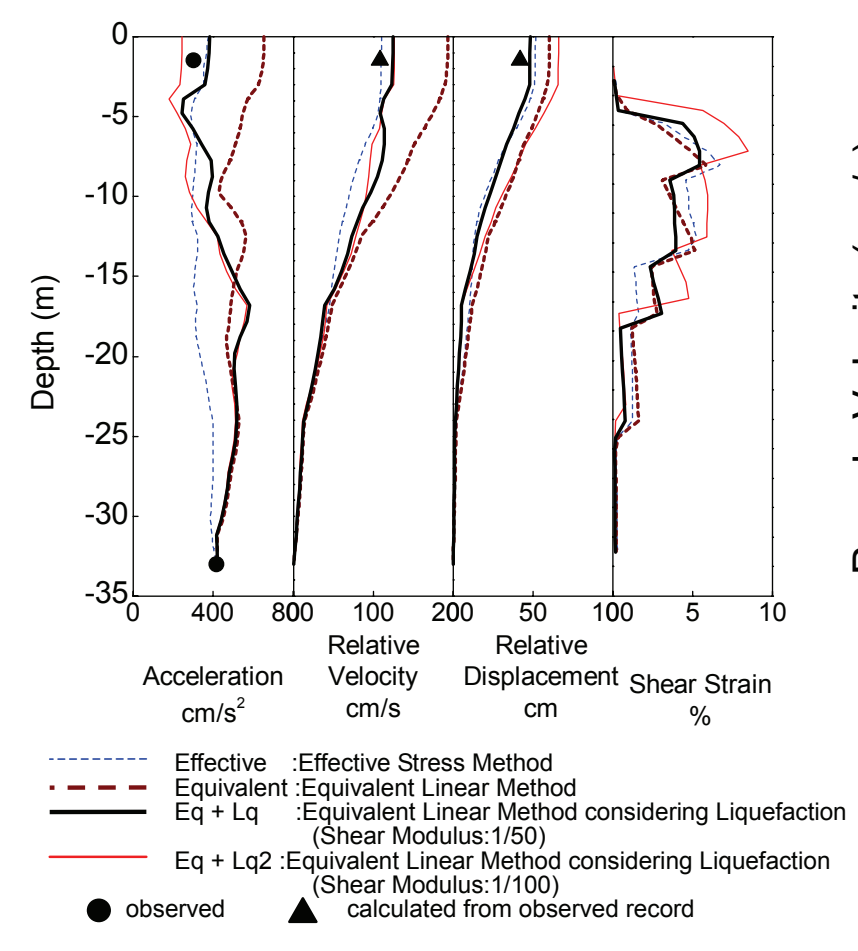

Fig. 6 Maximum response distribution at East Kobe Bridge

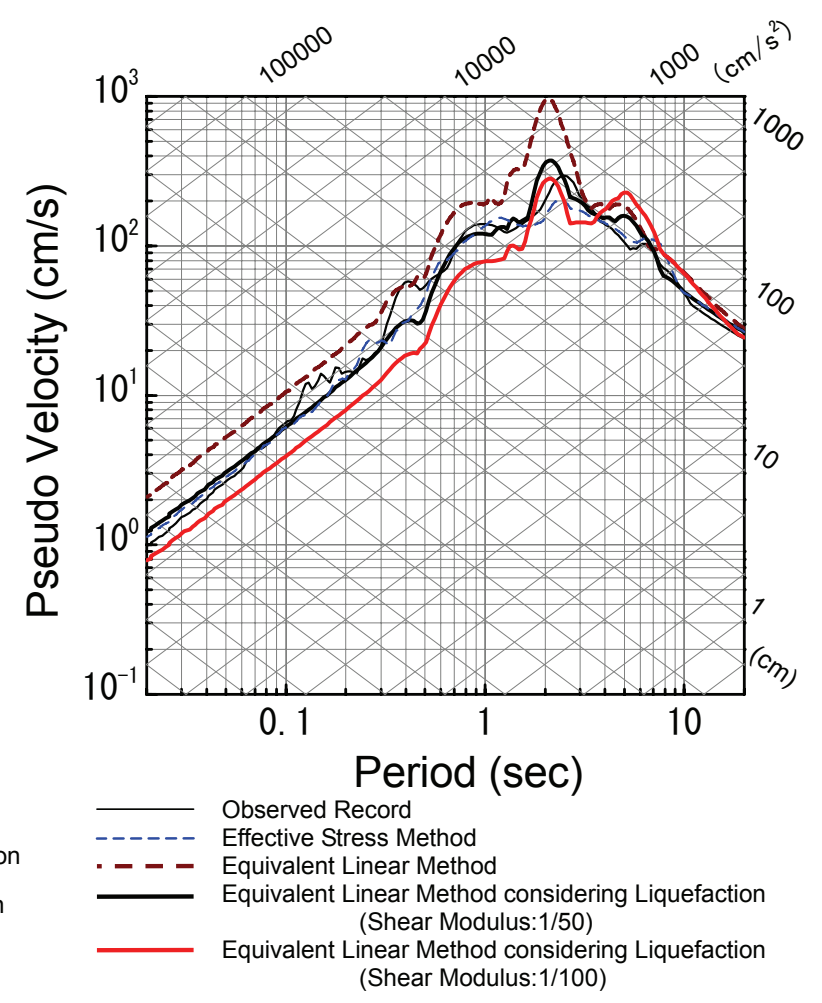

Fig. 7 Pseudo velocity response spectra $(\mathrm{h}=5 \%)$ liquefaction is shown in Fig. 2. An equivalent linear method considering liquefaction in the iteration has also been proposed ${ }^{18)}$. Four reduction ratios in the shear modulus of $1 / 20,1 / 50,1 / 100$, and $1 / 200$ of the initial value were adopted for the liquefied layer in view of the Port Island case. The liquefaction strengths of decomposed granite soil were determined by SPT N-values. The SPT N-values were corrected in regard to the effective overburden pressure by Liao's method ${ }^{19)}$, and the liquefaction strengths were then estimated according to the method by Yoshimi et al. ${ }^{20)}$. The liquefaction strength and the element simulation results of the effective stress method are shown in Fig. 3. Table 2 shows the liquefaction parameters of reclaimed fill for the effective stress analysis. The nonlinear characteristics evaluated by referring to past tests on samples from the same island are shown in Fig. 4 with the test results. The waves of G.L.-34m at East Kobe Bridge were rotated to N334E, the span direction of the building to be analyzed later.

\section{(3) Shear modulus in liquefied layer}

Figure 1 shows the converged shear modulus excepting the liquefied layer and the result of liquefaction potential assessment obtained by the first equivalent linear analysis. The masado layer has a high potential of liquefaction. Based on these results, equivalent linear analysis considering liquefaction, where the shear modulus of the liquefied layer was reduced, was conducted. Figure 5 shows the acceleration time histories of the surface ground (G.L.-2m) obtained by the analysis compared with the observed records and the results 
of effective stress analysis and the first equivalent linear analysis. Also, the maximum response distributions and pseudo velocity response spectra with 5\% damping are shown in comparison in Figs. 6 and 7 , respectively.

Equivalent linear analysis considering liquefaction, where the shear moduli of the liquefied layers were set at $1 / 50$ or $1 / 100$ of the initial value, was then conducted. In the acceleration time histories at the ground surface, the extended predominant period and reduced amplitude from the latter half of the main phase were well explained, though the phase was delayed in the first half of the main phase, because a constant shear modulus was given throughout the analysis. Also, the maximum responses agreed well with those of the observed record and effective stress analysis. The shear strain was $3 \%$ to $7 \%$, also coinciding with them. Comparing the response spectra of these analyses, it is found that the shape of the spectra approaches the observed value, particularly in the predominant period. It is considered that the equivalent linear method is useful for examining the seismic behavior of liquefied ground, provided that the reduction in the shear modulus is properly estimated.

With a small reduction in the shear modulus to $1 / 20$, the analysis led to large amplitudes, being incapable of evaluating the liquefaction similarly to ordinary equivalent linear analysis. On the contrary, with a large reduction to $1 / 200$, the predominant period was longer than the observed period, suggesting that the reduction was excessive.

According to the above-mentioned evaluation, the maximum responses, waveforms, and response spectra agreed with the observed record when the shear modulus was reduced to $1 / 50$ or $1 / 100$ of the initial value. It suggests that the shear modulus of the masado layer decreased to between 1/50 and $1 / 100$ of the initial value and that the shear strain reached $3 \%$ to $6 \%$ at the East Kobe Bridge site during the Hyogoken-Nambu earthquake, which was the same or slightly higher than in the Kobe Port Island case.

\section{DAMAGE TO A PILE FOUNDATION STRUCTURE}

(1) Evaluation of response of pile foundation structure by multi-lumped mass model considering liquefaction

\section{a) Analytical model}

As the behavior of pile foundations is governed by the displacement of a liquefied soil layer, the effect of liquefaction on the piles can be evaluated by adequately estimating the shear modulus during liquefaction and carrying out an analysis with the adequately estimated values. Equivalent linear analysis considering liquefaction is therefore extended to a multi-lumped mass model, with which analyses are conducted to examine the applicability of this method to damage evaluation for a pile foundation structure.

The object is a damaged pile foundation structure $^{21)}$ located in the same reclaimed island as the East Kobe Bridge site. Miwa et al. ${ }^{1)}$ elucidated the process and causes of the damage by effective stress analysis using a multi-lumped mass model. In this method, the response of the free field was calculated first by the one-dimensional effective stress analysis, and the changes in the stiffness of soil springs and interaction springs due to the changes in the effective stress were considered by inputting the time histories of the excess pore water pressure obtained from the response of the free field into the constitutive equations of the springs. These equations were expressed as functions of the effective stress in the layer.

In the present study, the following analysis was conducted in contrast with this detailed analysis: One-dimensional equivalent linear analysis of the ground was conducted first. The shear moduli of the free field and surrounding field were then set by applying the converged shear moduli obtained by the 1-D analysis. The shear modulus of the liquefied layer was reduced considering liquefaction. Interaction springs were set by applying the Mindlin-II solution based on these shear moduli. A multi-lumped mass model considering liquefaction was made as stated above, with which a dynamic response analysis of pile foundations was conducted. The shear modulus of the liquefied layer was set at $1 / 100$ of the initial value. The strainenergy-proportional-type damping was used in the multi-lumped mass analysis. The analytical model is shown in Fig. 8. The masado layer under the ground water level at G.L.-3.8m down to G.L.-14.75m was liquefiable. The dynamic characteristics of soils were the same as those shown in Fig. 4. The input motion for the multi-lumped mass model was the waveform of the observed motion at G.L. $-27 \mathrm{~m}$ obtained from the 1-D equivalent linear analysis of the ground.

\section{b) Evaluation of the response of pile foundations}

Figure 9 shows the distribution of the maximum response values of the ground and structure computed by the multi-lumped mass model considering liquefaction equivalently compared with the effective stress method ${ }^{1)}$. The buildup of the excess pore water pressure and the liquefaction 


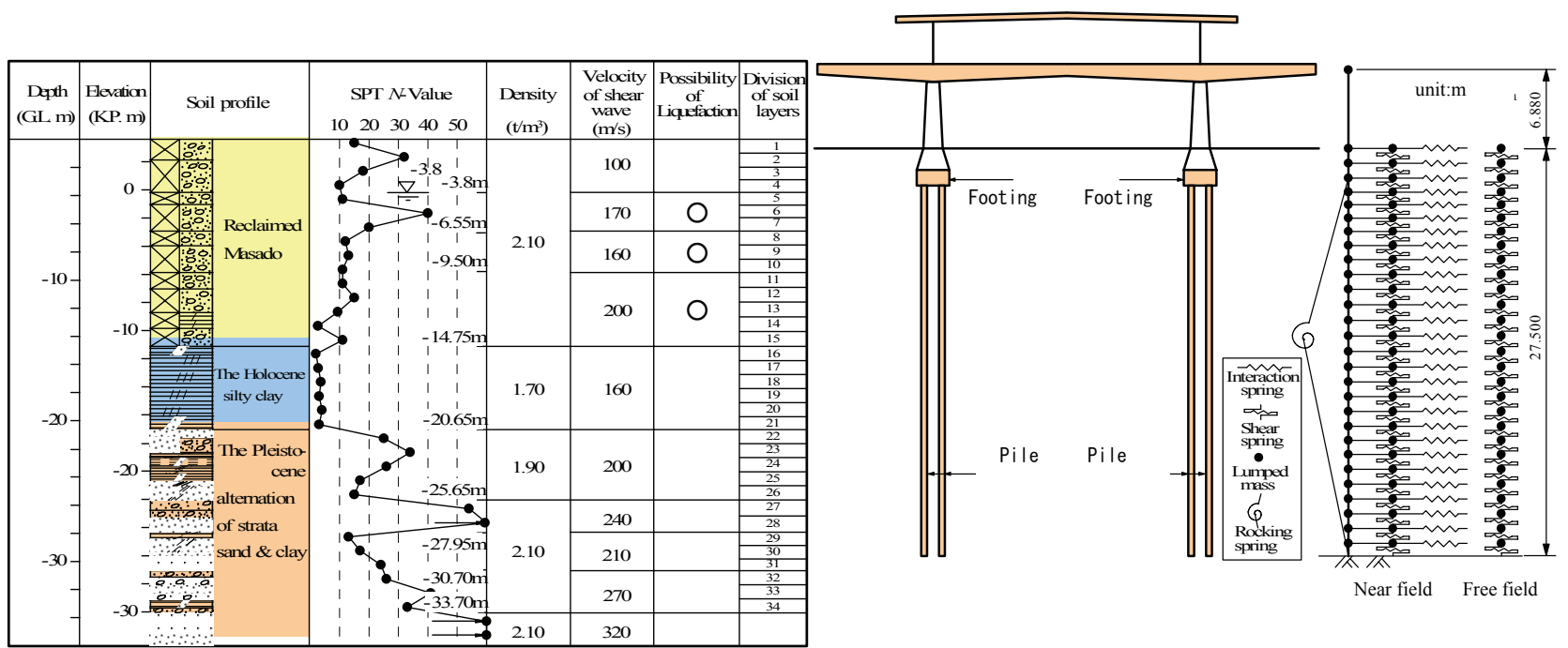

(G.L. $\pm \mathrm{m}=\mathrm{KP} .+36 \mathrm{~m})$

Fig. 8 Soil profile and analytical model for soil-pile-structure interaction

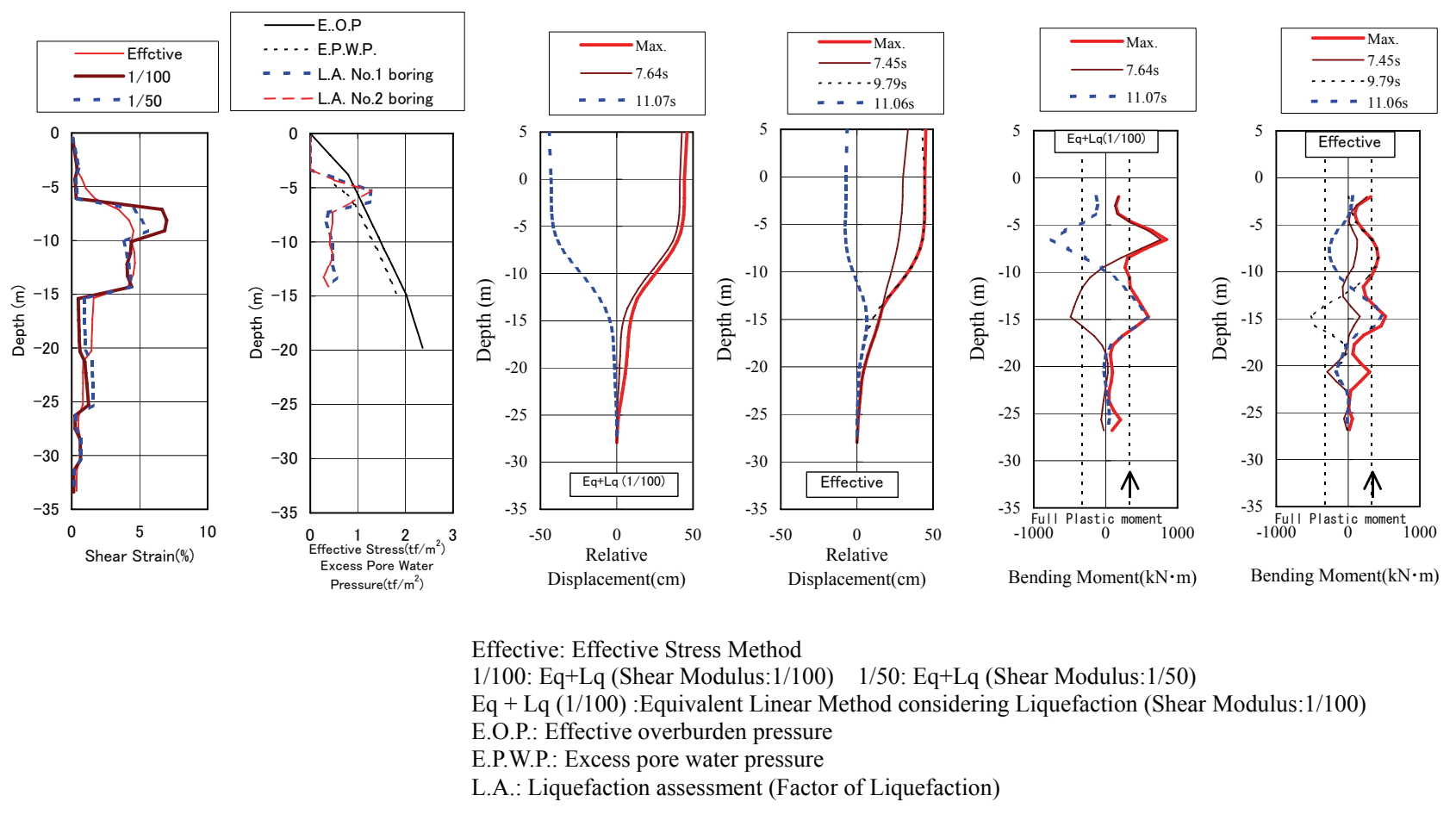

Fig. 9 Response of soil and piles computed by dynamic soil-pile-structure analysis

potential assessment suggest that the soil layer between G.L.- $6.55 \mathrm{~m}$ and G.L.- $14.75 \mathrm{~m}$ liquefied. As for the bending moment, the values at the times when the acceleration of the superstructure is at a maximum (around $7.64 \mathrm{sec}$ ) and the ground displacement is at a maximum (around $11.07 \mathrm{sec}$ ) are shown in the figure. The at a maximum relative displacements agree well with those by the effective stress analysis. However, whereas the relative displacement at the maximum acceleration of the superstructure has subsided by the effective stress analysis, the values remain as large as the maximum at that time by the equivalent linear analysis, due to the constant shear modulus. While the bending moments are generally slightly larger, particularly large values appear at around G.L.-6m to G.L.- $7 \mathrm{~m}$ 

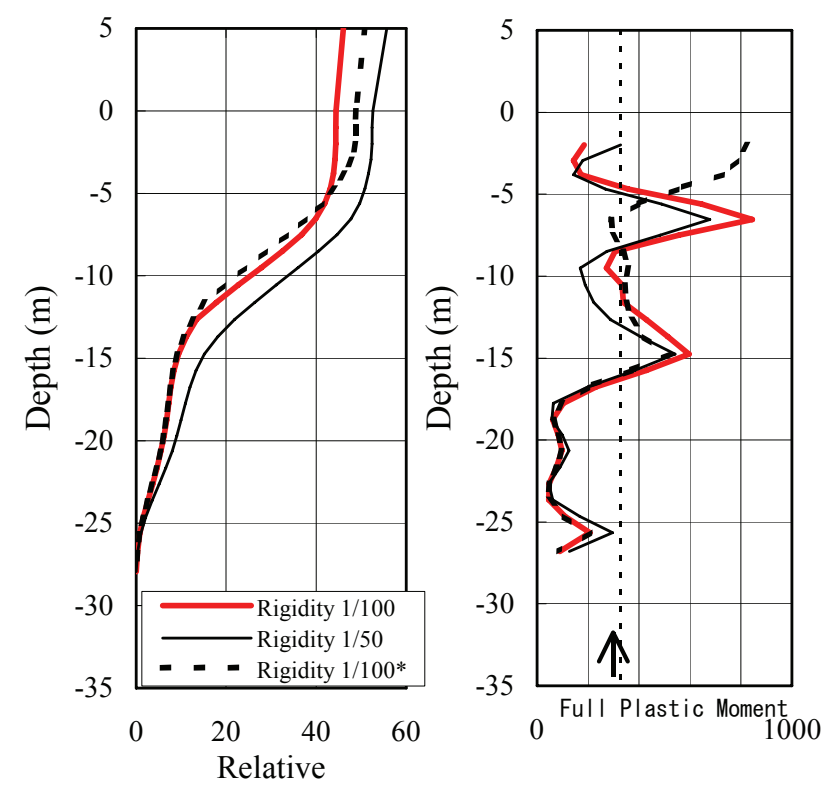

Displacement $(\mathrm{cm})$

Bending Moment $(\mathrm{kN} \cdot \mathrm{m})$

*In case of Fill under ground water level fully liquefied

Fig. 10 Effect of thickness of liquefied layer on response of soil and pile

and around G.L. $-15 \mathrm{~m}$, at which the maximum values similarly appear by the effective stress analysis. The results in the time zone in which piles are strongly affected by the ground displacement in the liquefaction process coincide well with the results by the effective stress analysis. The fact that these responses are almost the same as the maximum responses indicates that the pile responses are primarily governed by the ground displacement during and after the liquefaction process. The behavior of piles during the time zone of large inertial force differs from that by effective stress analysis, because of the constant shear modulus in the equivalent linear analysis, but the response values in this time zone are equal to or lower than the maximum value. The difference in the distributions of the bending moment by both methods around G.L. $-7 \mathrm{~m}$ can be attributed to the abrupt changes in the shear strain along the depth in the liquefied layer by the equivalent linear analysis in contrast to the smooth changes by the effective stress analysis.

Figure 10 shows the pile responses with the shear modulus reduced to $1 / 50$ and $1 / 100$ to compare the effect of different shear moduli on the pile response. The bending moments differ only by $10 \%$ to $20 \%$ by the difference between shear moduli of $1 / 50$ and $1 / 100$. It is therefore considered that the pile response can be appropriately evaluated in actual design even if the estimated shear modulus of the liquefiable layer scatters from $50 \%$ to $200 \%$. Figure 10 also shows the case where the masado layer under the water level between G.L.-3.8 $\mathrm{m}$ and G.L.$6.55 \mathrm{~m}$ also liquefies. The distribution of the bending moment around the pile head level widely differs from the original case. Whether or not liquefaction occurs affects the response more strongly than the scatter of the shear modulus.

In this light, equivalent linear analysis using a multi-lumped mass model considering liquefaction is found capable of evaluating damage to pile foundations, which is predominantly affected by ground displacement during liquefaction, though it is difficult to evaluate the damage process in the time domain. This method can therefore be an effective tool for actual design. Moreover, a combination of 1-D equivalent linear analysis considering liquefaction with the response displacement method also leads to similar results without dynamic analysis using a multi-lumped mass model, though figures cannot be shown in this paper. This technique can be another simple and useful design tool.

\section{SHEAR MODULUS AND SHEAR STRAIN IN VARIOUS SITES AND THEIR RANGES}

\section{(1) Shear modulus and shear strain in various sites}

Shear modulus and shear strain is considered to depend on the liquefaction strength of soil and characteristics of strong ground motions, such as their strength and duration. The values used for the above-mentioned case regarding the HyogokenNambu earthquake may not necessarily be relevant to other cases. For this reason, the shear modulus and shear strain during liquefaction are evaluated for other sites during the Hyogoken-Nambu earthquake and other strong motion observation sites during other earthquakes. The cases of the Wildlife site ${ }^{22)}$ during the Superstitions Hill Earthquake is presented as an example. The soil profile and observation array at the Wildlife site are shown in Fig. 11. Figure $\mathbf{1 2}$ shows the time histories of the acceleration at the ground surface, excess pore water pressure at P5 and shear strain computed from the relative displacement between the surface and underground by doubly integrating the acceleration time histories. The shear strain peaks when the main phase of acceleration settles and the buildup of excess pore water pressure increases to liquefaction. This figure reveals that the ground displacement during a strong motion is especially large in the process of 


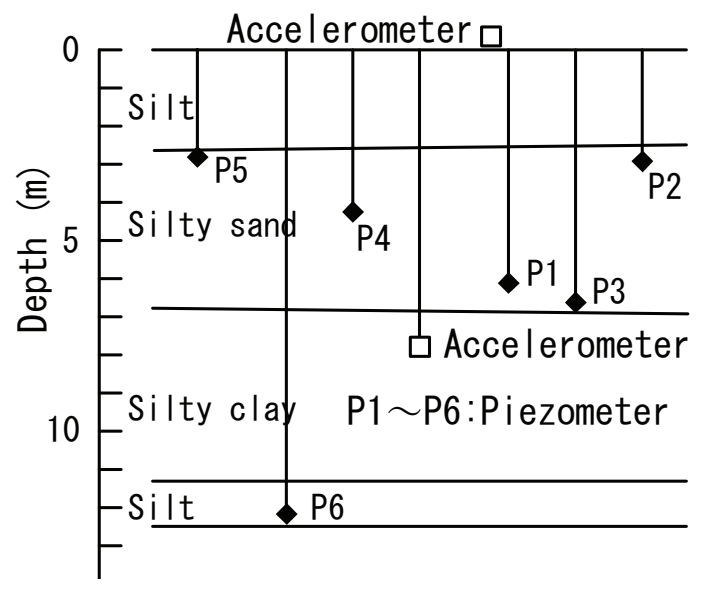

Fig. 11 Soil profile and observation array at Wildlife site
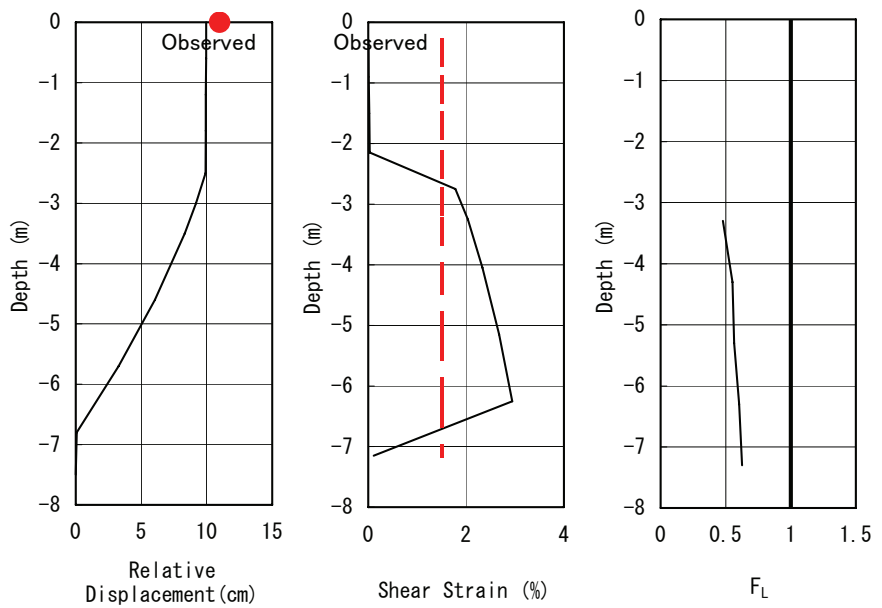

Fig. 13 Time histories of 1987 Superstitions Hill earthquake at Wildlife site

liquefaction even by waves not as strong as those of the Hyogoken-Nambu earthquake, which caused liquefaction with only the first two or three cycles. The averaged shear strain including non-liquefied layers is $1.5 \%$. The results of equivalent linear analysis considering liquefaction applied to this site are shown in Fig. 13. The results with a shear modulus of $1 / 100$ of the initial value agree well with the relative displacement at the surface, with the shear strain of the liquefied layer being $2 \%$ to $3 \%$. This result is in harmony with the observed record showing an averaged shear strain of $1.5 \%$ including non-liquefied layers. Figure $\mathbf{1 4}$ compares the pseudo velocity response spectrum with 5\% damping with that of the observed record after liquefaction. Both response spectra agree well. Similar analyses were conducted at the other sites.
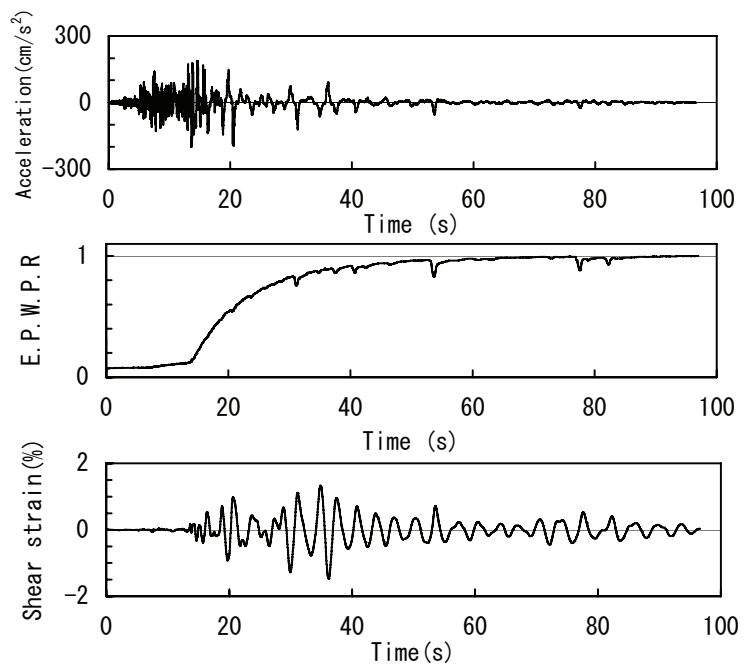

Fig. 12 Response of soil computed by dynamic analysis at Wildlife site

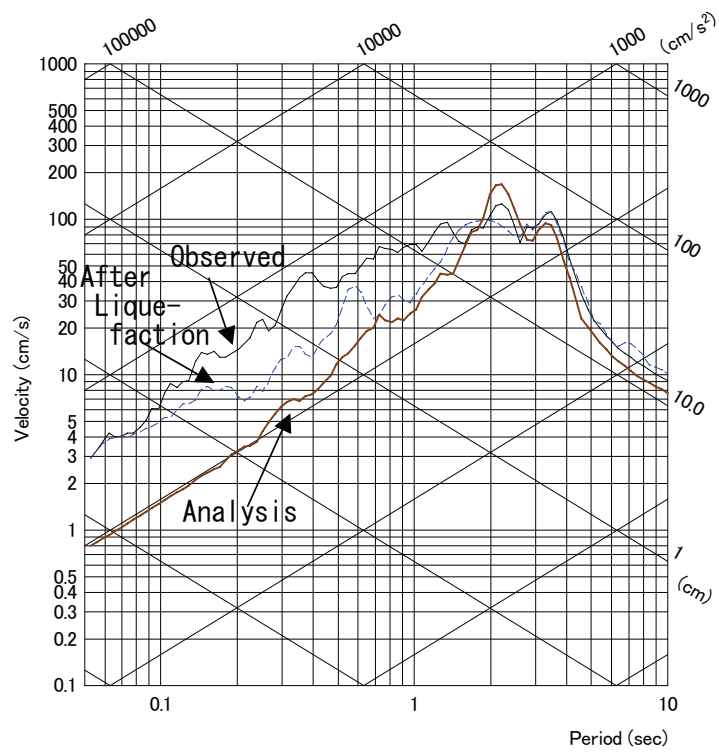

Fig. 14 Pseudo velocity response spectra $(\mathrm{h}=5 \%)$ of observed and computed acceleration of 1987 Superstitions Hill earthquake at Wildlife site

\section{(2) Range of the shear modulus for liquefied ground}

Evaluated shear modulus and shear strain during liquefaction at some sites struck by various earthquakes are tabulated in Table 3. For loose sand and masado with an equivalent $\mathrm{N}$-value of 10 to 15 or less, the shear modulus is evaluated to decrease to $1 / 100$ or less, with the shear strain increasing to a high level of $2 \%$ to $6 \%$ when the liquefaction resistance factor FL is under 0.6 , which indicates severe liquefaction. When FL is 0.6 to 0.8 , the shear modulus and shear strain are evaluated to be about $1 / 50$ and $1 \%$, respectively. For dense sand with an equivalent $\mathrm{N}$-value of about 22 with FL ranging between 0.8 and 1.0, the shear modulus is evaluated to decrease to $1 / 40$, with the shear strain reaching $1.0 \%$ to $1.5 \%$. For a ground improved by 
Table 3 Reduction of shear modulus and shear strain in liquefied sites

\begin{tabular}{|c|c|c|c|c|c|c|c|c|}
\hline Site & Earthquake & Soil & $\begin{array}{c}\text { Observed } \\
\text { maximum } \\
\text { velocity } \\
(\mathrm{cm} / \mathrm{s})\end{array}$ & \begin{tabular}{|c|} 
Equivalent \\
SPT N- \\
Value \\
(Na) \\
\end{tabular} & $\begin{array}{l}\text { Shear } \\
\text { strain } \\
(\%)\end{array}$ & $\begin{array}{c}\text { Reduction of } \\
\text { shear } \\
\text { modulus }\end{array}$ & FL & Evaluation Method \\
\hline East Kobe Bridge & $\begin{array}{l}1995 \text { Hyogoken-Nambu } \\
\text { earthquake }\end{array}$ & $\begin{array}{l}\text { Decomposed granite } \\
\text { soil }\end{array}$ & 89 & 11 & $3-6$ & $1 / 50-1 / 100$ & $0.3-0.5$ & $\begin{array}{l}\text { Observed record, effective stress analysis and } \\
\text { equivalent linear analysis considering liquefaction }\end{array}$ \\
\hline Fukaehama & $\begin{array}{l}1995 \text { Hyogoken-Nambu } \\
\text { earthquake }\end{array}$ & $\begin{array}{l}\text { Decomposed granite } \\
\text { soil }\end{array}$ & $(102)$ & 14 & $4-6$ & $1 / 100$ & $0.3-0.5$ & $\begin{array}{l}\text { Damage investigation, Observed record, effective } \\
\text { stress analysis and equivalent linear analysis } \\
\text { considering liquefaction }\end{array}$ \\
\hline Port Island & $\begin{array}{l}1995 \text { Hyogoken-Nambu } \\
\text { earthquake }\end{array}$ & $\begin{array}{l}\text { Decomposed granite } \\
\text { soil }\end{array}$ & 91 & 14 & $2-5$ & $1 / 50-1 / 100$ & $0.3-0.5$ & $\begin{array}{l}\text { Observed record, effective stress analysis and } \\
\text { equivalent linear analysis considering liquefaction } \\
\text { (shear strain is estimated only for liquefied layer, } \\
\text { so shear strain Is different from the value on P2) }\end{array}$ \\
\hline Nishinomiya ham & $\begin{array}{l}1995 \text { Hyogoken-Nambu } \\
\text { earthquake }\end{array}$ & $\begin{array}{l}\text { Decomposed granite } \\
\text { soil (Improved) }\end{array}$ & $(121)$ & 18 & 5 & $1 / 40-1 / 50$ & 0.6-0.9 & $\begin{array}{l}\text { Effective stress analysis and equivalent linear } \\
\text { analysis considering liquefaction }\end{array}$ \\
\hline Rokko Island & $\begin{array}{l}1995 \text { Hyogoken-Nambu } \\
\text { earthquake }\end{array}$ & Mud rock & (74) & 18 & $3-5$ & $1 / 40$ & $0.8-0.9$ & $\begin{array}{l}\text { Effective stress analysis and equivalent linear } \\
\text { analysis considering liquefaction }\end{array}$ \\
\hline Wildlife & $\begin{array}{l}1987 \text { Superstitions Hill } \\
\text { earthquake }\end{array}$ & Loose silty sand & 31 & 11 & $2-3$ & $1 / 100$ & $0.4-0.6$ & $\begin{array}{l}\text { Observed record, effective stress analysis and } \\
\text { equivalent linear analysis considering liquefaction }\end{array}$ \\
\hline Sakaiminato 1 & $\begin{array}{l}2000 \text { Tottoriken-Seibu } \\
\text { earthquake }\end{array}$ & Medium sand & 57 & 15 & $2-5$ & $1 / 100$ & $0.5-0.6$ & $\begin{array}{l}\text { Observed record, effective stress analysis and } \\
\text { equivalent linear analysis considering liquefaction }\end{array}$ \\
\hline Sakaiminato 2 & $\begin{array}{l}2000 \text { Tottoriken-Seibu } \\
\text { earthquake }\end{array}$ & Dense medium sand & 57 & 22 & $1-1.5$ & $1 / 40$ & $0.8-0.9$ & $\begin{array}{l}\text { Observed record, effective stress analysis and } \\
\text { equivalent linear analysis considering liquefaction }\end{array}$ \\
\hline Kushiro Port & $\begin{array}{l}1993 \text { Kushiro-Oki } \\
\text { earthquake }\end{array}$ & Dense sand & 61 & 23 & 1 & $1 / 30-1 / 40$ & $0.9-1.0$ & $\begin{array}{l}\text { Observed record, effective stress analysis and } \\
\text { equivalent linear analysis considering liquefaction }\end{array}$ \\
\hline Kusiro west port & $\begin{array}{l}1994 \text { Hokkaido Toho-oki } \\
\text { earthquake }\end{array}$ & Loose sand & 19 & 11 & 1 & $1 / 50$ & $0.6-0.8$ & $\begin{array}{l}\text { Observed record and equivalent linear analysis } \\
\text { considering liquefaction }\end{array}$ \\
\hline
\end{tabular}

compaction with FL ranging between 0.7 and 0.9 , the shear modulus is evaluated to be between $1 / 40$ and $1 / 50$.

The relationship between the liquefaction resistance factor FL and the ratio of the reduced shear modulus to the initial value is shown in Fig. 15. The relationship between the shear strain and the ratio of the reduced shear modulus to the initial value is shown in Fig. 16. The shear modulus decreases as FL decreases. For dense sand, the reduction in FL tends to stop at 0.6 , while the shear modulus ratio levels off at 1/50 of the initial value. For loose sand, FL reduces to 0.3, while the shear modulus ratio further decreases to $1 / 100$. Taking notice of shear strain, the shear strain of loose sand varies depending on the degree of liquefaction: 1$2 \%$ and $2-6 \%$ when the shear modulus is $1 / 50$ and $1 / 100$ of the initial value, respectively. For dense sand, the shear modulus stops its reduction at $1 / 50$, with the shear strain settling at $1-1.5 \%$. The shear modulus reduction and shear strain level thus vary depending on the denseness of sand. This can be judged by FL as shown in Fig. 15. Note that the shear strain of a ground improved by compaction is high, though the shear modulus was 1/50 of the initial value. This is because the only data available were those of the Hyogoken-Nambu earthquake with intense ground motions and because only numerical analysis including uncertain factors was used for the estimation of shear strain. This requires further study.

In this paper, a larger strain level than those found in conventional dynamic characteristics curves is shown in the relationship between the shear modulus reduction and the shear strain. With a shear strain of around $1 \%$, the shear moduli in this relationship are lower than conventional cases because of the significant buildup of the excess pore water pressure. Few data of dynamic characteristics with such a large strain level are currently available, due to difficulty in testing.

Kazama $^{23)}$ et al. showed the relationship between shear modulus reductions and shear strain including the influence of the buildup of excess pore water pressure based on undrained cyclic shear test under a constant strain amplitude condition. For masado, four cycles of loading is reported to lead to a reduction in the shear modulus to $1 / 50$ and approximately $1 / 100$ with a shear strain of $1 \%$ and $2-3 \%$, respectively, which is in harmony with the results shown here. In the Recommendations for Design of Building Foundation ${ }^{24)}$, an equivalent Nvalue $(\mathrm{Na})$ is used as a rough index to a reduction in the shear modulus, where $\mathrm{Na}=20$ is $1 / 40, \mathrm{Na}=10$ is about $1 / 130$. These values also agree well with the results of the present study.

Though it is difficult to explain the reduction in the shear modulus and the shear strain of various 

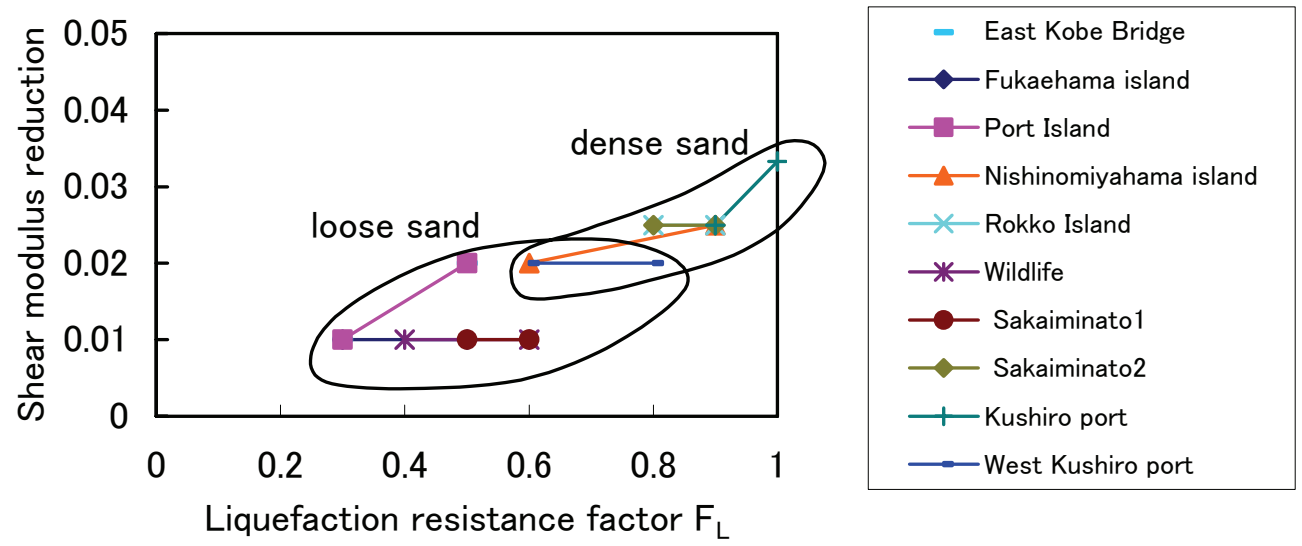

Fig. 15 Relation of liquefaction resistance factor FL and shear modulus reduction
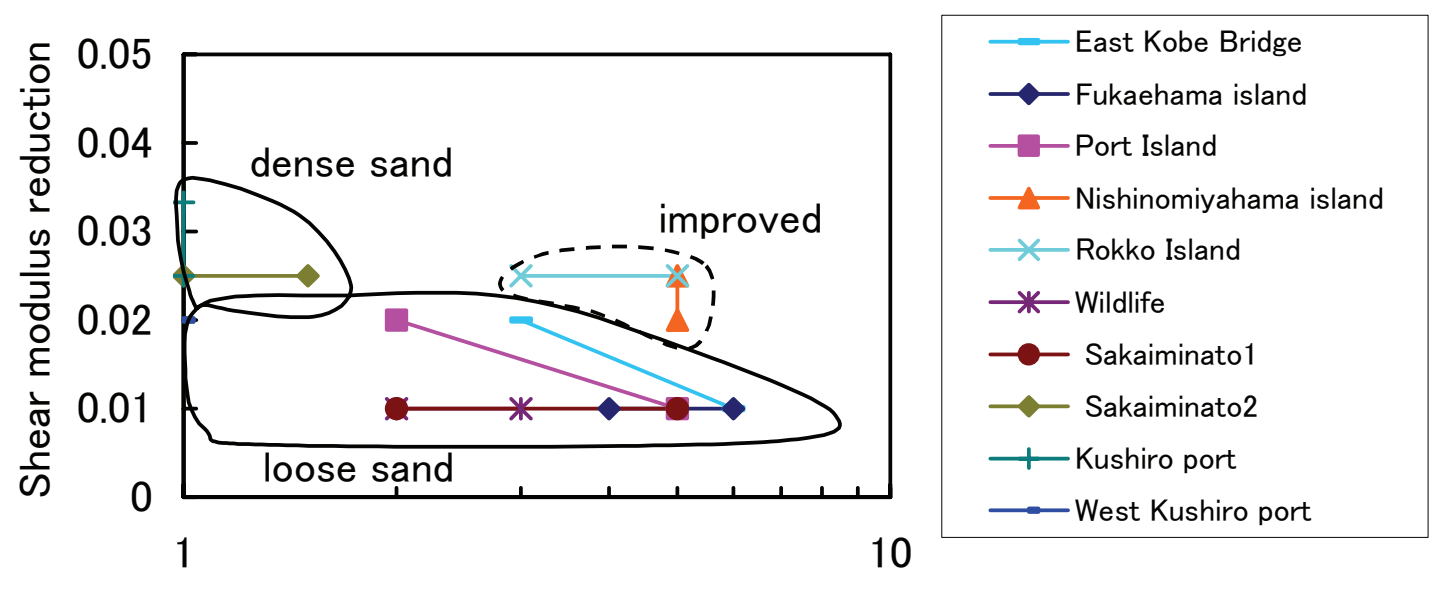

Shear Strain

Fig. 16 Relation of shear strain and shear modulus reduction

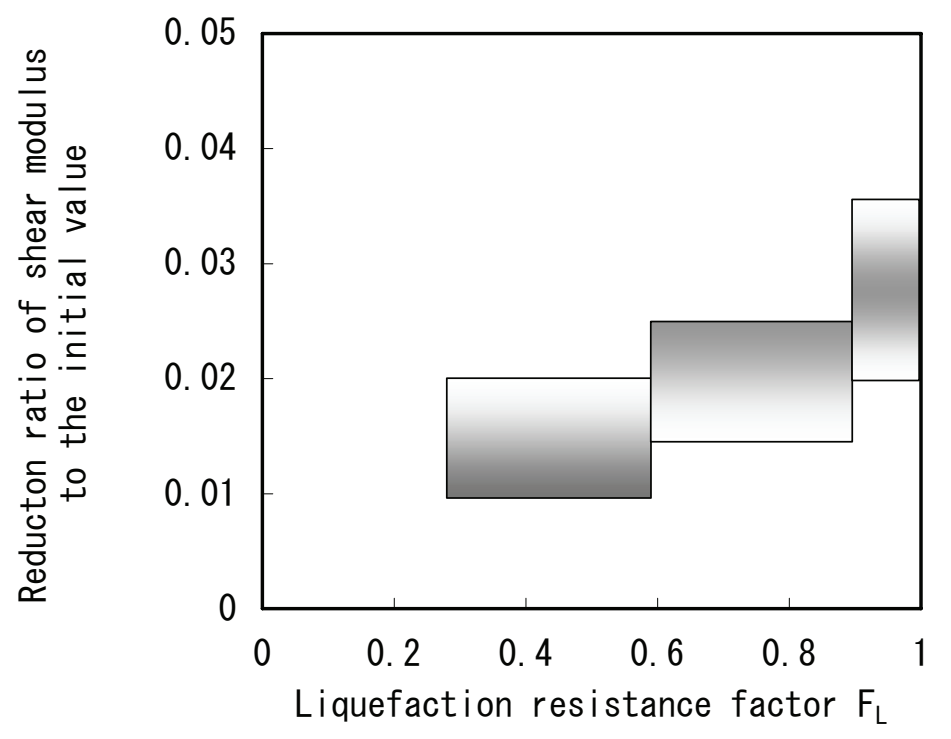

Fig. 17 Relationship between liquefied level and reduction ratio of shear modulus to the initial value for evaluation of response of foundation structure 
soils in a lump, evaluation of shear modulus and shear strain during liquefaction at some sites struck by various earthquakes has so far led to similar reductions in the shear modulus in accordance with FL regardless of the soil type. In view of the fact that differences in the soil conditions are considered in the evaluation of liquefaction resistance, it is possible to evaluate the reduction of shear modulus, thereby evaluating the response of the ground and pile foundations, by using the relationship shown here. A relationship between FL and the ratio of reduced shear modulus to the initial value for evaluating the seismic behavior of soils by equivalent linear analysis is proposed in Fig. 17. The accuracy of this method will be improved by accumulating test data and observation records, which have been insufficient to date due to the scarcity of tests and events causing such a large strain level.

The shear modulus and shear strain during liquefaction were evaluated in regard to some sites struck by various earthquakes. Based on these data, the relationship between FL and the ratio of reduced shear modulus to the initial value was proposed for evaluating the seismic behavior of soils by equivalent linear analysis.

\section{CONCLUSIONS}

As pile behavior is predominantly affected by the ground behavior in a liquefied ground, the authors exhibited the possibility of evaluating the behavior of liquefied ground by equivalent linear analysis considering the reduction of shear modulus due to liquefaction. By using this method, the shear modulus and shear strain of a site liquefied during the Hyogoken-Nambu earthquake were estimated based on observed records. The reduction in the shear modulus was then incorporated in a multilumped mass model, and the validity of the method was examined by applying it to a damage analysis in comparison with the effective stress method. Also, the shear modulus and shear strain during liquefaction were evaluated in regard to other sites struck by various earthquakes based on observed records. Finally, a relationship between FL and the reduction in the shear modulus was proposed for evaluating the seismic behavior of soils by equivalent linear analysis. The following conclusions were obtained:

1) The behavior of liquefied ground can be evaluated by equivalent linear analysis considering the reduction of shear modulus due to liquefaction. At first, a normal equivalent linear analysis is conducted. A liquefaction potential assessment for liquefiable layers is then made based on the result of the equivalent linear analysis. A shear modulus considering liquefaction is given to the liquefied layer, and a converged value obtained from the analysis is given to other layers. A linear analysis is then carried out to evaluate the amplification of the ground containing a liquefied layer. This twostep analysis is proposed as "equivalent linear analysis considering liquefaction."

2) The "equivalent linear analysis considering liquefaction" was applied to the East Kobe Bridge site to evaluate the reduction in the shear modulus and the shear strain. It revealed that the shear modulus of the masado layer decreased to $1 / 50$ to $1 / 100$ of the initial value and that the shear strain reached $3 \%$ to $6 \%$ at this site during the Hyogoken-Nambu earthquake.

3) The shear springs of a multi-lumped mass model were evaluated by the reduced shear modulus considering liquefaction. "Equivalent linear analysis considering liquefaction" for a multi-lumped mass model was applied to damaged pile foundations. It was found that the damage to pile foundations predominantly affected by ground displacement during liquefaction can be adequately evaluated, though it is difficult to evaluate the damage process in the time domain. This method can be an effective tool for evaluating pile foundations in a liquefied layer.

4) The shear modulus and shear strain during liquefaction were evaluated in regard to other sites hit by the Hyogoken-Nambu earthquake and other strong motion observation sites hit by other earthquakes. It was found that the shear modulus decreased to $1 / 100$ or lower and the shear strain reached as high as $2 \%$ to $6 \%$ in loose sand, whereas the shear modulus decreased to $1 / 50$ and the shear strain reached $1.0 \%$ to $1.5 \%$ in dense sand. Based on these data, the relationship between FL and the reduced shear modulus was proposed for evaluating the seismic behavior of soils by equivalent linear analysis.

ACKNOWLEDGMENT: The authors thank the Public Works Research Institute for providing the seismic records of the East Kobe Bridge Station.

\section{REFERENCES}

1) Miwa, S., Ikeda, T. and Oh-oka H.: Analysis of Steel Pipe Pile Foundation Damage in Liquefied Reclaimed Land during 1995 Hyogoken-Nambu Earthquake, Journal of Japan association for earthquake engineering, Vol.4, No.1, pp.5-22, 
2004. (in Japanese)

2) Kazama, M. and Yanagisawa, E.: Evaluation of Stress Strain Relationship of the Ground during Hyogo-ken Nambu Earthquake using Vertical Array Observation Records at Kobe Port Island, Proc. of the 23rd JSCE Earthquake Engineering Symposium-1995, pp.185-188, 1995. (in Japanese)

3) Kokusho, T., Satoh, K. and Matsumoto, M.: Nonlinear Dynamic Response of Soil Ground Hyogo-ken Nambu Earthquake, Tsuchi-to-Kiso, Vol.43, No.9, pp.39-43, 1995. (in Japanese)

4) Yoshida, I. and Kurita, T.: Back Analysis of Dynamic Soil Properties of Port Island with the Observation Data during Hyogo-ken Nambu Earthquake, Tsuchi-to-Kiso, Vol.43, No.9, pp.44-48, 1995. (in Japanese)

5) Kawase, H., Satoh, T., Fukutake, T. and Irikura, K.: Borehole Records Observed at the Port Island in Kobe during the Hyogo-ken Nanbu Earthquake of 1995 and Its Simulation, Journal of Structural and Construction Engineering, Transactions of AIJ, No.475, pp.83-92, 1995. (in Japanese)

6) Suzuki, T.: Identification Analysis for Dynamic Soil Properties using Strong Motion Records at the Kobe Port Island, Proc. of the 31st Japan National Conference on Geotechnical Engineering, pp.1089-1090, 1996. (in Japanese)

7) Morio, S., Kitazumi, A. and Kusakabe, S.: Wave Propagation Characteristics of Recorded Accelerations at the Port Island Site, Proc. of the 31st Japan National Conference on Geotechnical Engineering, pp.1093-1094, 1996. (in Japanese)

8) Miyata, M., Nozu, A. and Iai, S.: Time History of Shear Wave Velocity at Port Island Site during and after the Great Hanshin Earthquake, Proc. of the 31st Japan National Conference on Geotechnical Engineering, pp.1131-1132, 1996. (in Japanese)

9) Mochizuki, M., Kamiyama, M. and Yoshida, M.: Nonlinear Response Characteristics of Vertical Array Observation Records at Port Island form the View Point of Cross Correlation, Proc. of the 51st Annual Conference of JSCE,1B, pp.434-435, 1996. (in Japanese)

10) Miwa, S., Ikeda, T. and Onimaru, S.: Study on seismic behavior of reclaimed ground during Hyogoken-Nanbu earthquake (Part2: Shear strain of liquefied layers of weathered granite soil "Masado"), Proc. 33rd Japan National Conf. on Geotech. Engrg., JGS., pp.877-878, 1998. (in Japanese).

11) Hagiwara, R., Usami, A. and Tabuchi, Y.: Strong-motion acceleration records from Public Works in Japan, Technical Note of PWRI, No.64, 1995. (in Japanese)
12)Iai, S., Matsunaga, Y. and Kameoka, T.: Strain Space Plasticity Model for Cyclic Mobility, Soils and Foundations, Vol. 32, No. 2, pp. 1-15, 1992.

13)Towhata, I. and Ishihara, K.: Modelling soil behavior under principal stress axes rotation, Proc. of 5 th Int. Conf. on Num. Methods in Geomechanics, Vol.1, pp. 523-530, 1985.

14) Schnabel, P.B., Lysmer, J. and Seed, H.B.: SHAKE, A computer program for earthquake response analysis of horizontally layered sites, Report EERC Univ. of California Berkeley, 1972.

15) Hayashi, H., Nishikawa, J., Taniguchi, K., Miwa, S. and Ikeda, T.: A study on Ground Seismic Behavior using Liquefaction Array Observation Records, Proc. of 10th Japan Earthquake Engineering Symposium, pp.1217-1222, 1998. (in Japanese)

16) Miwa, S., Ikeda, T., Shimamoto, E. and Numata, A.: Earthquake Response Evaluation of Sites in Liquefied Areas, Proc. of 2nd Int. Symposium on the Effect of Surface Geology on Seismic Motion, Vol.3, pp.1471-1478, 1998.

17) Miwa, S., Ikeda, T. and Oh-oka, H.: Study on Seismic Behavior of Liquefied Ground using Strong Motion Array Records of the 1995 Hyogoken-Nambu Earthquake, Proc. 12WCEE, No.1325, 2000.

18) Udaka, T., Uchida, O., Tanaka, N. and Sato, T.: Liquefaction Analysis of Soil System Based on the MultiEquivalent Linear method, Tsuchi-to-Kiso, Vol.48, No.8, pp.5-8, 2000. (in Japanese)

19) Liao, S. S. C. and Whitman, R. V.: Overburden Correlation Factors for SPT in Sand, J Geotech Engng, ASCE, Vol.112, No.3, pp.373-377, 1986.

20) Yoshimi, Y., Tokimatsu, K., Kaneko, O. and Makihara, Y.: Undisturbed Cyclic Shear Strength of a Dense Niigata Sand, Soils and Foundations, Vol.24, No.4, pp.131-145, 1984.

21) Kato, F., Satake, K., Hirose, T., Oh-Oka, H. and Tokimatsu, $\mathrm{K}$.: Investigation for steel pipe pile foundation damaged by lateral spreading in Hyogoken-Nanbu Earthquake, Proceedings of the 10th Earthquake Engineering Symposium, pp. 365-370,1998. (in Japanese)

22) Holzer, T. L., Youd, T. L. and Hanks, T. C.: Dynamics of Liquefaction during 1987 Superstition Hills, California Earthquake, Science, Vol.244, pp.56-59, 1989.

23) Kazama, M., Suzuki, T. and Yanagisawa, E.: Evaluation of Dissipation Energy Accumulated in Surface Ground and its Application to Liquefaction Prediction, Journal of Geotechnical Engineering, JSCE, No.631/III-48, pp.161177, 1999. (in Japanese)

24) Architectural Institute of Japan: Recommendation for design of building foundation (Second edition), pp.68-69, 2001.

(Received June 1, 2005) 